\title{
EVALUATION OF THE COAGULATION FLOATATION PROCESS FOR INDUSTRIAL MINERAL OIL WASTEWATER TREATMENT USING RESPONSE SURFACE METHODOLOGY (RSM)
}

\author{
E. KWEINOR TETTEH \& S. RATHILAL \\ Department of Chemical Engineering, Durban University of Technology, South Africa
}

\begin{abstract}
Recovery of oil and water from industrial mineral oil wastewater for reuse is a means of conserving water and energy for economic growth and sustainability. The effluent generated from a local South African oil refinery is characterized by a high content of four water parameters, namely chemical oxidation demand (COD), soap oil and grease (SOG), turbidity (NTU) and total suspended solids (TSS). The goal of this study is to optimize the coagulation floatation process using a polymeric coagulant for the efficient reduction of contaminant concentrations. The response surface methodology (RSM) coupled with the Box-Behnken design (BBD) was adapted to evaluate the effects and interactions of three factors: $\mathrm{pH}$, coagulant dosage and floatation time to maximize the efficiency of the coagulant to the response of the four water qualities. A standard jar test procedure of coagulation floatation was adapted to improve the water quality. Quadratic and linear models were generated for COD with SOG and NTU with TSS as the responding variables, respectively. In addition, analysis of variance (ANOVA) shows that the model was significant with a $95 \%$ confidence level. The desirability from the experiment shows that at the optimum coagulant dosage of $50 \mathrm{mg} / \mathrm{L}$, about $70 \%$ of the initial wastewater contaminants were removed as compared with RSM at an optimum dose of $40 \mathrm{mg} / \mathrm{L}$ and $80 \%$ removal. This helps reduce chemical costs and upgrade the water quality. The BBD-RSM serves as a statistical tool for evaluation, verification and decision-making for the response feedback and helps identify the most important factor to control in order to enhance the treatment efficiency of the process.
\end{abstract}

Keywords: Coagulation, floatation, response surface methodology, soap oil and grease

\section{INTRODUCTION}

Rapid urbanization and industrialization have created pollution potentials within residential areas and its environment, and hence, environmental restrictions have become more stringent. In addition, most industrial wastewater treatment companies face the challenge to acquire sound and efficient treatment techniques to comply with the environmental regulations and balance their sustainable development and economic viability. In this scenario, removal of mineral oil (MO) from water before downstream treatment is desirable as the oil recovered can be reprocessed for sale as low-grade oil.

To meet the demand for petroleum products, about $60 \%$ of South African crude oil is being imported from Saudi Arabia, Nigeria and Angola. However, South Africa, having the second-largest oil refinery capacity in Africa after Algeria, has six refineries such as Cape town refinery (Chevron), Engen refinery (Petronas), Sapref refinery (Shell and BP), Sasol refinery, National petroleum refinery of South Africa (Natref) and Mossel Bay Gas to liquid (GTL Petro SA) [1]. These refineries and petrochemical plants generate large quantities of wastewater during the crude oil exploration. When left untreated before discharge into the sewer, they cause environmental degradation, health hazards and threaten the ecosystem. To protect the environment and have a healthy economy, there is an urgent need to evaluate the treatment process and improve upon it to meet the designated discharge limits $(50 \mathrm{mg} / \mathrm{L})$ and avoid surcharge bills imposed by the municipalities [2, 3]. 
The industrial wastewater (IW) is a dark yellowish, cream-coloured, highly turbid, pungent smelling, and has a high content of chemical oxygen demand (COD), soap oil and grease (SOG) and total dissolved and suspended solids $[4,5]$. In addition, although there is a diverse range of technologies for breaking up oil/water emulsions, each technology has its own disadvantage in separating oil from water [6]. Therefore, it requires supportive physicochemical techniques which include acidification $\left(\mathrm{HCl}, \mathrm{H}_{2} \mathrm{SO}_{4}, \mathrm{H}_{3} \mathrm{PO}_{4}\right.$ ), coagulation (coagulants, polymers) and floatation (dissolved air floatation, electro floatation, dispersed floatation) [7, 8].

Coagulation floatation has been reported to have the potential to treat IW to meet regulatory limits and improve the effluent quality before discharge or recycling back to the process line for reuse at low cost [7, 9]. Coagulation involves the addition of a coagulant to the IW flowed by subsequent agitation to bring the negatively charged oil droplets to agglomerate to form flocs. However, the selection of the coagulant type depends on the water quality, and underdose or overdose might affect the oil droplet floc size formation [6, 10]. It is worthwhile to add that the oil droplet floc size and the effluent quality depend on the amount of the dissolved air added to the emulsion at a complete saturated pressure [4]. Breaking the stability of the emulsion through the use of a coagulant followed by microbubble addition (floatation) has been widely applied in the wastewater and IW treatment plant due to its merit over sedimentation [2, 7, 9]. According to Zouboulis [9], at a saturated pressure of $350 \mathrm{kPa}$, a bubble size of 10-100 micron is expected to occur which increases the floatation efficiency.

Dissolved air floatation (DAF) is a physical technique that generates a large number of microbubbles for the release of dissolved air from supersaturated water in a saturator tank into a floatation zone. This increases the air bubble to oil droplet attachment with a high rising velocity and, due to its low buoyancy, moves to the surface of the water, leaving the bottom water clean to be discharged as effluent (Fig. 1).

The general strategy for optimization in the IW treatment process is to improve upon the performance with less cost for the end usage of the water. The emerging paradigm in the analytical evaluation and the graphical perspective of a mathematical model has led to the response surface methodology (RSM) [4, 11-13].

From previous studies, RSM is an effective optimization tool used to evaluate and identify the effect and relationship that exists between multivariables on the response using

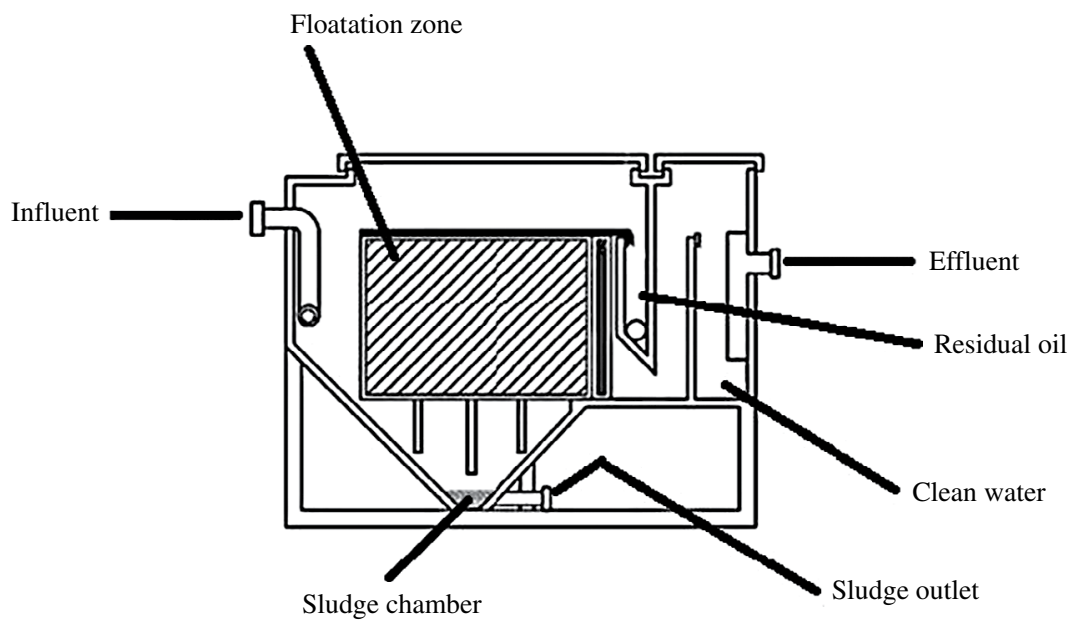

Figure 1: Schematic diagram of industrial wastewater DAF unit. 
Table 1: Selecting RSM design style.

\begin{tabular}{cl}
\hline RSM design style & Factors to consider \\
\hline $\begin{array}{c}\text { Three-level full } \\
\text { factorial }\end{array}$ & $\begin{array}{l}\text { Each factor requires three levels. } \\
\text { This design requires more experimental runs. }\end{array}$ \\
\hline CCD CCI & $\begin{array}{l}\text { Each factor requires five levels. } \\
\text { The model predictions are poor compared to the CCF and the CCC. } \\
\text { Limitation of using only the points specified in the experiment. } \\
\text { CCF }\end{array}$ \\
& $\begin{array}{l}\text { Three levels are required for each variable. } \\
\text { The model predictions are better than CCI. }\end{array}$ \\
& $\begin{array}{l}\text { Five levels are required for each variable. } \\
\text { This design requires points outside of the constraints of the original } \\
\text { factorial design. } \\
\text { Provides better predictions than the CCI and the CCF. } \\
\text { Three levels are required for each variable. } \\
\text { Requires fewer runs than the CCD for } 3<n<4 . \\
\text { Five levels are required for each variable. } \\
\text { The experimental domain expands with the addition of other factors. } \\
\text { Requires fewer runs than all of the DOE above. }\end{array}$ \\
\end{tabular}

quantitative data obtained from the experimental design. This results in the derivation of an empirical response model fitted on a polynomial equation, specifically second-order regression [11]. The significance of each input variable and its impact on the response are then evaluated with the ANOVA. However, to design the experiment, there are some factors to consider which depend on the availability of resources, the number of factors considered and their level and also the type of the RSM design style, such as three-level full factorial design, central composite design (CCD), the Doehlert design (DD) and the Box-Behnken design (BBD). These design styles are shown in Table 1.

In a previous work by Tetteh et al. [14], the BBD was used to design experiments for $\mathrm{pH}$, coagulant dosage and floatation time to address the approach of data analysis, modelling and evaluating the effects of the independent variables on the response. The aim of this article also introduces the experimenter to the alternative to control and reduce the coagulant dosage to enhance an efficient treatment effluent quality and to compare the results from the response model prediction to that of the experimental results, and establish the accuracy of the response models developed.

\section{MATERIALS AND METHODS}

\subsection{DAF jar test}

The principle of acidification, coagulation and floatation was done using phosphoric acid, polyaluminium sulphate (PAS) and DAF jar test at a rapid mixing rate of $250 \mathrm{rpm}$ for $2 \mathrm{~min}$ utes. Promoting floc growth was achieved at a slow agitation speed of $30 \mathrm{rpm}$ for 15 minutes. A saturated pressure of $350 \mathrm{kPa}$ was used in allowing the floatation time set to elapse. The analysis was performed in accordance with the South African Bureau of Standards (SABS) technique 1051 [14, 15]. 
Table 2: The RSM-Box-Behnken design matrix.

\begin{tabular}{lrcr}
\hline \multirow{2}{*}{ Input variables } & \multicolumn{3}{c}{ Coded levels $(\mathrm{X})$} \\
\cline { 2 - 4 } & -1 & 0 & 1 \\
\hline $\mathrm{X}_{1}: \mathrm{pH}$ & 4 & 5 & 6 \\
$\mathrm{X}_{2}:$ Coagulant dosage $(\mathrm{mg} / \mathrm{L})$ & 30 & 40 & 50 \\
$\mathrm{X}_{3}:$ Floatation time $(\mathrm{min})$ & 10 & 15 & 20 \\
\hline
\end{tabular}

\section{$2.2 \mathrm{RSM}$}

The Design Expert (10.0.3) software was used for the design of the experiments for the RSM, statistical analysis and modelling of the experimental data collected. The matrix of the experiments with the combination of different levels of the independent variables is shown in Table 2. The relationship between the responses and the inputs was fitted on a polynomial quadratic model represented in the form of eqn (1).

$$
Y=f\left(x_{1}, x_{2}, x_{3}--x_{n}\right)+\varepsilon
$$

Where $Y$ is the response, $f$ is the unknown function of the response, $x_{1}, x_{2}, x_{3}--x_{n}$ are the independent variables that affect the response and $n$ is the number of factors. The $e$ also represents the statistical error that is not accounted for by the function.

The responses and the expression of the percentage measured values of the result were calculated using eqn (2).

$$
\mathrm{Y}_{\mathrm{n}}(\%)=\frac{\mathrm{Y}_{0}-\mathrm{Y}_{0}}{\mathrm{Y}_{0}} \times 100
$$

Where $\mathrm{Y}_{\mathrm{n}}, \mathrm{y}_{0}$ and $\mathrm{y}_{\mathrm{n}}$ represents the demanded response (water quality), initial and final water quality respectively. The response is an indicator of efficiency. Before and after each run of the coagulation floatation process, samples were taken and analysed for COD $\left(\mathrm{Y}_{1}\right)$, SOG $\left(\mathrm{Y}_{2}\right)$, TSS $\left(\mathrm{Y}_{3}\right)$ and turbidity $\left(\mathrm{Y}_{4}\right)$.

\section{RESULTS AND DISCUSSION}

To avoid judgemental bias and misrepresentation of the input variable effects on each response, the analyses of the data were performed according to the BBD standard order run depicted in Table 3. The most important variables and their optimal region were selected based on the statistical analysis. The factors had a significant effect on the response within the boundaries tested.

Addition of PAS as the coagulant contains highly charged polymeric aluminium species and monomers; hence, increasing the dosage increases the oil droplet charge either by losing or by gaining more protons depending on the $\mathrm{pH}$ of the solution [9]. This means that because of the polymerization reaction, the negative charge of the oil droplets is progressively replaced by the positive charge of PAS according to eqn (3)

$$
\mathrm{Al}^{3+} \rightarrow \mathrm{Al}(\mathrm{OH})^{2+} \rightarrow \mathrm{Al}(\mathrm{OH})_{2}^{+} \rightarrow \mathrm{Al}(\mathrm{OH})_{3} \rightarrow \mathrm{Al}(\mathrm{OH})_{4}^{-}
$$


Table 3: The Box-Behnken design matrix.

\begin{tabular}{rrrrrrrr}
\hline Standard run & \multicolumn{3}{c}{ Input factors } & \multicolumn{5}{c}{ Response \% removal } \\
\hline 1 & $\mathrm{X}_{1}$ & $\mathrm{X}_{2}$ & $\mathrm{X}_{3}$ & $\mathrm{Y}_{1}$ & $\mathrm{Y}_{2}$ & $\mathrm{Y}_{3}$ & $\mathrm{Y}_{4}$ \\
\hline 2 & 0 & 0 & 0 & 85 & 84 & 81 & 75 \\
3 & 0 & 0 & 0 & 86 & 86 & 84 & 74 \\
4 & 0 & -1 & 1 & 85 & 72 & 74 & 68 \\
5 & -1 & 1 & 0 & 89 & 89 & 80 & 72 \\
6 & 1 & 0 & -1 & 84 & 77 & 79 & 70 \\
7 & 0 & 0 & 0 & 89 & 88 & 82 & 73 \\
8 & 0 & 1 & 1 & 86 & 90 & 85 & 73 \\
9 & 1 & 1 & 0 & 86 & 90 & 84 & 71 \\
10 & -1 & 0 & 1 & 82 & 85 & 84 & 72 \\
11 & 0 & 0 & 0 & 87 & 92 & 86 & 72 \\
12 & 1 & 0 & 1 & 82 & 86 & 85 & 71 \\
13 & -1 & -1 & 0 & 80 & 75 & 72 & 69 \\
14 & -1 & 0 & -1 & 83 & 86 & 81 & 70 \\
15 & 1 & -1 & 0 & 82 & 74 & 73 & 69 \\
16 & 0 & 1 & -1 & 88 & 91 & 85 & 73 \\
17 & 0 & -1 & -1 & 84 & 73 & 75 & 64 \\
\hline
\end{tabular}

Therefore, in the context of the coagulation mechanism, PAS dosage increases the possibility of charge neutralization of the oil droplet due to adsorption and absorption of the contaminants present in the IW. Thus, an increase in precipitation increases the percentage removal of the contaminants.

\subsection{Response model}

The optimization process was carried out using the $\mathrm{BBD}$, as mentioned previously, where $\mathrm{Y}$ and $\mathrm{X}$ accounts for the four responses and three input variables, respectively. After the selection of the design and the models, the ANOVA was used to check the quality and accuracy of the response models $[4,11]$. Furthermore, the probability $(\mathrm{P}>\mathrm{F}$-value) of a variable not affecting the response was found to be been less than 0.05 with a $95 \%$ confidence level. This tells us that the ANOVA can be used to evaluate four individual response models as expressed as follows:

$$
\begin{gathered}
Y_{1}=-19.75+40.38 X_{1}-1.28 X_{2}+2.33 X_{3}-4 X_{1}^{2}+0.02 X_{2}^{2}-0.08 X_{3}^{2} \\
Y_{2}=-101.11+41.78 X_{1}-3.63 X_{2}-4.33 X_{1}^{2}+0.034 X_{2}^{2}
\end{gathered}
$$




$$
\begin{gathered}
Y_{3}=55.35+0.625 X_{2} \\
Y_{4}=45.32+0.56 X_{2}
\end{gathered}
$$

\subsection{BBD diagnostic and 3D plots}

Although there were no combined or cross-interactional effects of the input variable terms on the response models generated (eqns 4-7), it was found that some of the combined or cross-interactions have no significant effects on the response. The fit of the polynomial was also expressed as the coefficient of determination $R^{2}$ and the adjusted $R^{2}$. The $R^{2}$ defines the overall performance of the model and for quality check purposes should be close to 1 . The reliabilities of the developed models were also shown in a diagnostic plot such as predicted versus actual plot. From Fig. 2a, most points were distributed near the straight line, indicating the quadratic models developed for (a) COD and (b) SOG were significant. Figure 2b denotes the linear regression models for (c) TSS and (d) turbidity, where most points were not distributed around straight line, signifying that not all the levels of input variables had a significant effect on the response. The standard deviation was also taken into account, which was the difference between the predicted and experimental values and found to be less than $5 \%$.

\subsubsection{Three-dimensional (3D) plots}

The graphical representation of the response models forms the basis of the RSM to visualize the effects of the interactions [11]. The 3D plots also provide the surface area to observe the plot within which the process performs at optimal level due to the effects of the interaction of the factors in consideration. It was found that the centre points actually assist in the model's performance within the tested boundaries.

In this case, the floatation time was held constant (15 minutes), where the coagulant dosage and $\mathrm{pH}$ were evaluated. The optimal region for the most influenced factors was identified as
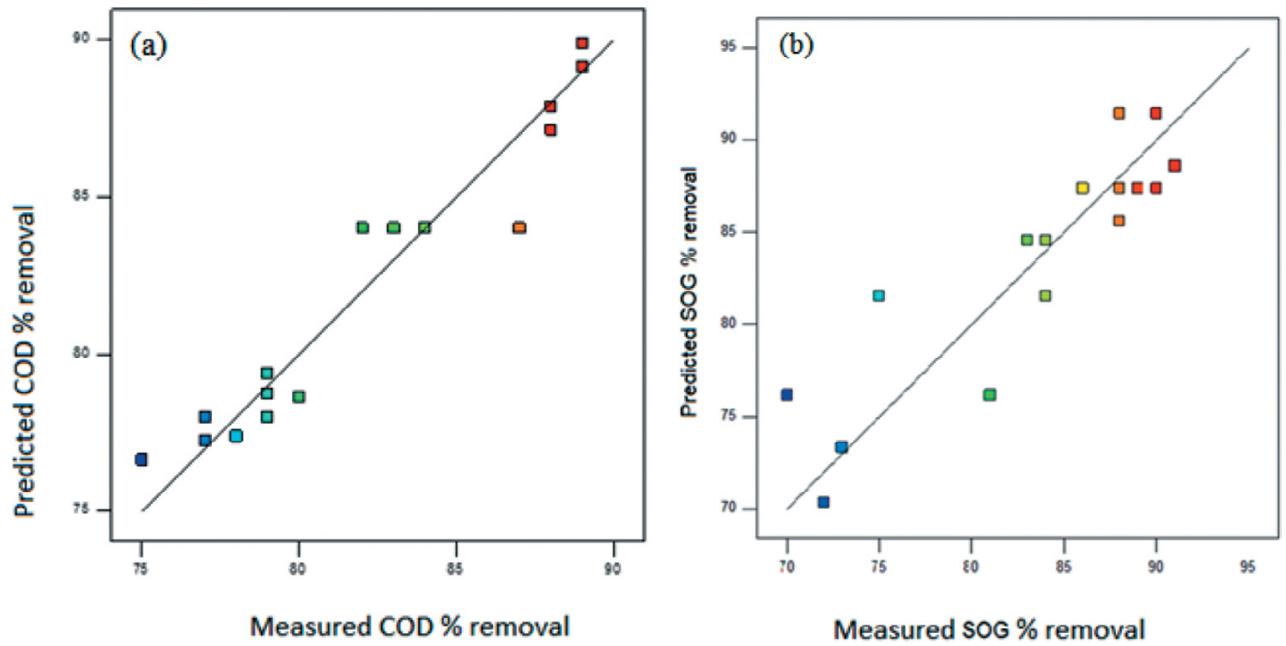

Figure 2a: Diagnostic plot of predicted versus actual for (a) COD (b) SOG percentage removal[WIT12]. 

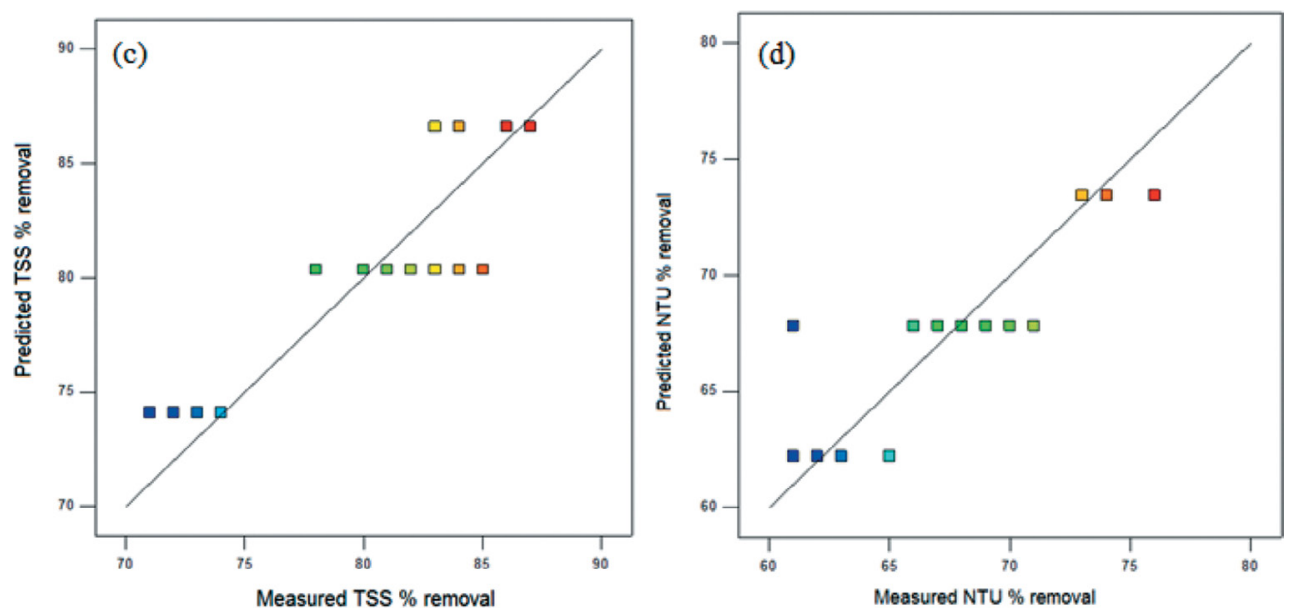

Figure 2b: Diagnostic plot of predicted versus actual for (c) TSS and (d) turbidity percentage removal.

$\mathrm{pH}$ (4.5-5.5) and coagulant dosage (35-45 mg/L), and in all cases, increasing the coagulant dosage produced a significant increase on the contaminant removals.

Figure 3 (3D plot and contour) for COD suggests that the PAS coagulant is effective in the acidic medium for the removal of COD. The distinct peaks with the curvatures suggest the sensitivity of the magnitudes of the model coefficient terms. However, the contour diverges with an increase in the coagulant dosage at constant $\mathrm{pH}(5)$ to obtain a maximum removal of $96 \%$. The $\mathrm{R}^{2}$ and adjusted $\mathrm{R}^{2}$ of the COD model were 0.8975 and 0.8745 respectively which makes the model significant.

Figure 4 shows that at a constant $\mathrm{pH}(5)$, increasing the coagulant dosage alters the sensitivity of the SOG removal to a maximum of $95 \%$. In this case the distinct peaks of the curvature suggest the optimum dosage is within the boundaries of the levels tested. The $\mathrm{R}^{2}$ and adjusted $\mathrm{R}^{2}$ values for the SOG model were 0.9635 and 0.9555 , respectively.
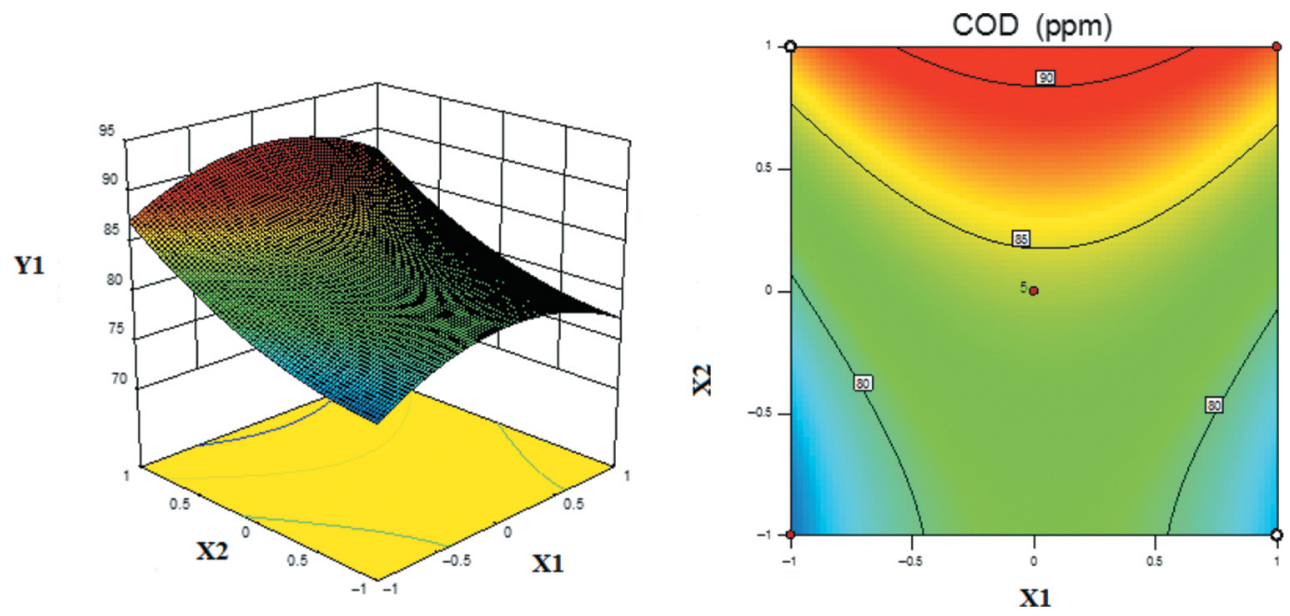

Figure 3: 3D plot for COD response model $\mathrm{pH}\left(\mathrm{X}_{1}\right)$ versus coagulant dosage $\left(\mathrm{X}_{2}\right)$ at constant floatation time of 15 minutes. 

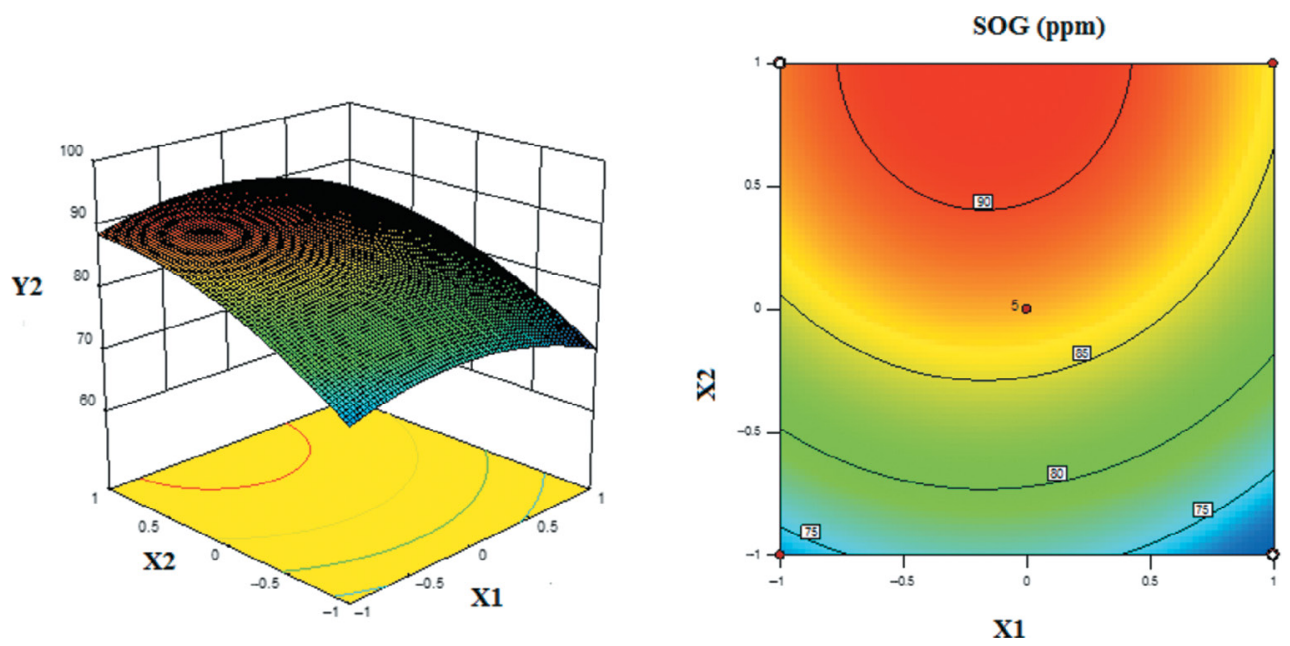

Figure 4: $3 \mathrm{D}$ plot for $\mathrm{SOG}$ response model; $\mathrm{pH}\left(\mathrm{X}_{1}\right)$ versus coagulant dosage $\left(\mathrm{X}_{2}\right)$ at constant floatation time of 15 minutes.

Figure 5 shows a steep slope curvature with linear contours indicating that TSS removal increases with an increase in coagulant dosage to a maximum removal of $90 \%$. The TSS model was significant due to the values for $\mathrm{R}^{2}$ and adjusted $\mathrm{R}^{2}$ of 0.9466 and 0.9235 respectively being very close to 1 .

Figure 6 shows that removal of turbidity increases with an increase in coagulant dosage, where the steep slope of the curvature is a linear contour. The significance of the turbidity model was also indicated by the value of $\mathrm{R}^{2}$ and adjusted $\mathrm{R}^{2}$ of 0.9563 and 0.9432 respectively.
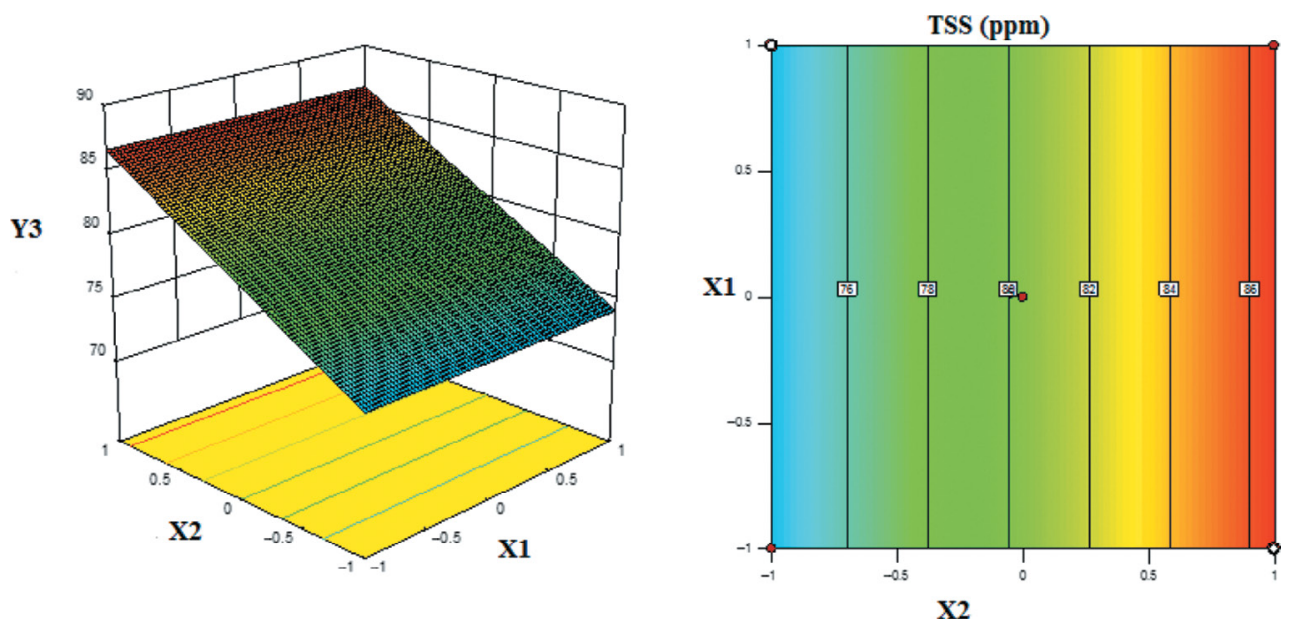

Figure 5: 3D plot for TSS response model; $\mathrm{pH}\left(\mathrm{X}_{1}\right)$ versus coagulant dosage $\left(\mathrm{X}_{2}\right)$ at constant floatation time of 15 minutes. 

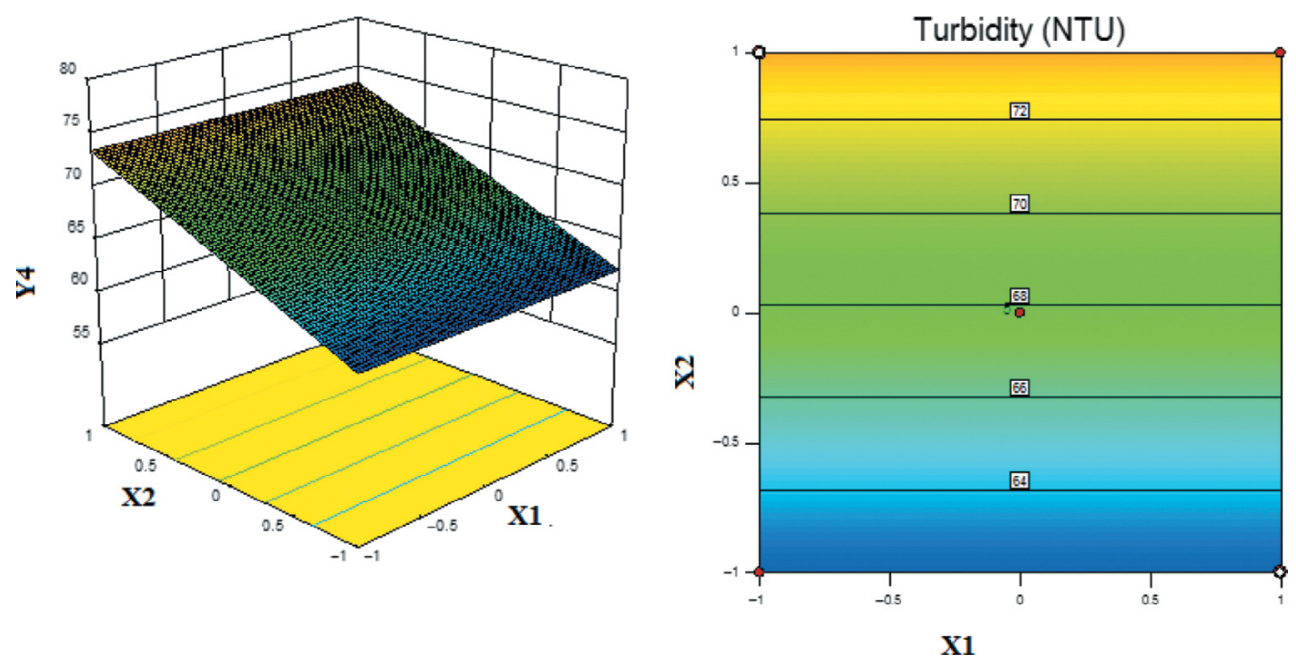

Figure 6: 3D plot for turbidity response; $\mathrm{pH}(\mathrm{X} 1)$ versus coagulant dosage (X2) at constant floatation time of 15 minutes.

The response models were then verified at coagulant dosages of 35,40 and $45 \mathrm{mg} / \mathrm{L}$. Figure 7 affirms the linear regression that exists between the coagulant dosage and all the responses, with $\mathrm{R}^{2}$ values of $0.8848,0.9555,0.9978$ and 0.9975 for $\mathrm{Y}_{1}, \mathrm{Y}_{2}, \mathrm{Y}_{3}$ and $\mathrm{Y}_{4}$ respectively. Furthermore, considering the direction to maximize the highest percentage removal, it was better to use a coagulant dosage of $40 \mathrm{mg} / \mathrm{L}$ than $45 \mathrm{mg} / \mathrm{L}$ due to the coagulant consumptions rate and economic viability. More so, it had over $90 \%$ removal of SOG which is the main contaminant of interest. Furthermore, from the experimental results, it was found that at a coagulant dosage of $50 \mathrm{mg} / \mathrm{L}$, the percentage removal of COD, SOG, TSS and turbidity was found to be $83 \%, 91 \%, 84 \%$ and $70 \%$, respectively. The optimum conditions for the model were therefore obtained at the input variable terms at level 0 . The percentage removal of COD, SOG, TSS and turbidity was found to be $89 \%, 93 \%, 86 \%$, and $74 \%$, respectively.

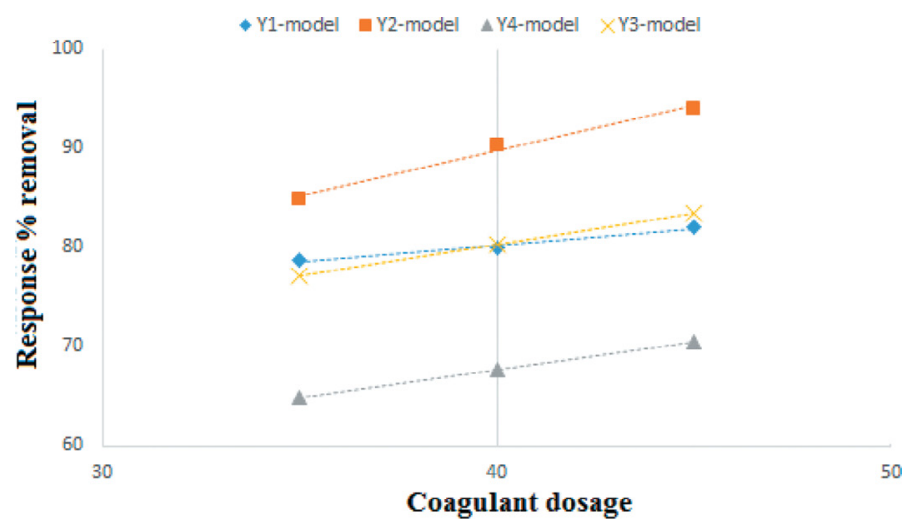

Figure 7: Validation of response surface models; Y1-COD, Y2-SOG, Y3-TSS and Y4-turbidity. 


\section{CONCLUSION}

The use of the RSM for the IW treatment process optimization has contributed to decisionmaking and reduction of operational costs. More so it assisted researchers and process engineers on the type of coagulant to use, reduced the number of experiments in the conventional method and focused on the major factor (coagulant dosage) that contributed to the highest effect on the process output. There existed a good correlation between the predicted and the experimental result with less than 5\% deviation. To enhance the control of the coagulant dosage, the $\mathrm{pH}$ (5) and the floatation time (15 minutes) must be kept constant. Therefore, coagulation floatation combined with RSM can cause a significant degree of accuracy on model prediction of an IW treatment process.

\section{ACKNOWLEDGEMENTS}

The authors wish to thank FFS Refiners Research and Development Department and Umgeni Water Process Evaluation Facility (PEF), South Africa, for their joint support in this project.

We also want to acknowledge the efforts of the following personalities - Ms Keshnee Naik (R\&D Chemist) and Mr Theolan Naidoo (Production Supervisor) at FFS Refiners (Pty) Ltd and Mr Lidenlani Sibiya (Process Engineer) at Umgeni Water - for facilitating this project with their expertise.

\section{REFERENCES}

[1] South Africa Yearbook, South Africa Yearbook (SAYB), 23rd ed., ed. Elias Tibane, Government Communications (GCIS): Pretoria, 500p., available at www.gcis.gov.za, 2015/2016 (accessed 23 January 2017).

[2] Welz, M., Baloyi, N. \& Deglon, D., Oil removal from industrial wastewater using flotation in a mechanically agitated flotation cell. Water $S A, 33(4)$, pp. 453-458, 2007. DOI: 10.4314/wsa.v33i4.52939.

[3] van Wilgen, B.W. \& Wannenburgh, A., Co-facilitating invasive species control, water conservation and poverty relief: Achievements and challenges in South Africa's Working for Water Programme. Current Opinion in Environmental Sustainability, 19, pp. 7-17, 2016. DOI: 10.1016/j.cosust.2015.08.012.

[4] Yuan, X., Liu, J., Zeng, G., Shi, J., Tong, J. \& Huang, G., Optimization of conversion of waste rapeseed oil with high FFA to biodiesel using response surface methodology. Renewable Energy, 33(7), pp. 1678-1684, 2008. DOI: 10.1016/j.renene.2007.09.007.

[5] Tetteh, E.K., Rathilal, S. \& Robinson, K. Treatment of industrial mineral oil wastewater Effects of coagulant type and dosage. Water Practice and Technology, 12(1), pp. 139-145. DOI: 10.2166/wpt.2017.021.

[6] Yu, L., Han, M. \& He, F. A review of treating oily wastewater. Arabian Journal of Chemistry, 2013. (In Press). DOI: 10.1016/j.arabjc.2013.07.020.

[7] Zodi, S., Potier, O., Lapicque, F. \& Leclerc, J.-P., Treatment of the industrial wastewaters by electrocoagulation: Optimization of coupled electrochemical and sedimentation processes. Desalination, 261(1-2), pp. 186-190, 2010. DOI: 10.1016/j.desal.2010.04.024.

[8] Megid, M.H.A., Amer, A.A.R. \& Elsayed, K.H., Coagulation and dissolved air floatation for treatment of oil-water emulsion. International Journal of Engineering Sciences, 3(12), pp. 120-129, 2014, available at www.tijournals.com (accessed 23 January 2017).

[9] Zouboulis, A.I. \& Avranas, A. Treatment of oil-in-water emulsions by coagulation and dissolved-air flotation. Colloids and Surfaces A: Physicochemical and Engineering Aspects, 172(1-3), pp. 153-161, 2000. DOI: 10.1016/S0927-7757(00)00561-6. 
[10] Berné, F., Cordonnier, J. \& Balvet, B.B. Industrial Water Treatment: Refining, Petrochemicals and Gas Processing Techniques, Gulf Professional: Houston, TX, 1995.

[11] Pambi, R. \& Musonge, P. Application of response surface methodology (RSM) in the treatment of final effluent from the sugar industry using Chitosan. WIT Transactions on Ecology and the Environment, 209, pp. 209-219, 2016. DOI: 10.2495/WP160191.

[12] Wang, J.-P., Chen, Y.-Z., Wang, Y., Yuan, S.-J. \& Yu, H.-Q. Optimization of the coagulation-flocculation process for pulp mill wastewater treatment using a combination of uniform design and response surface methodology. Water Research, 45(17), pp. 56335640, 2011. DOI: 10.1016/j.watres.2011.08.023.

[13] Li, N., Hu, Y., Lu, Y.Z., Zeng, R.J. \& Sheng, G.P. Multiple response optimization of the coagulation process for upgrading the quality of effluent from municipal wastewater treatment plant. Scientific Reports, 6, p. 26115, 2016. DOI: 10.1016/j.watres. 2010.08.032.

[14] Tetteh, E.K., Rathilal, S. \& Chollom, M.N. Pre-treatment of industrial mineral oil wastewater using Response Surface Methodology (RSM). 4th International Conference on Water \& Society, 5-7 June 2017, WIT Transactions: Seville, 2017.

[15] SANS-SABS. SANS 3696/ISO 3696, SOUTH AFRICAN NATIONAL STANDARD Water - Oil and grease content. SANS 6051, 2(2), pp. 1-7, 2007. DOI: 10.1016/S02210363(07)91337-2. 